\title{
Identidade coletiva negra e escolha eleitoral no Brasil
}

\author{
\begin{tabular}{c}
\hline \hline Gladys Mitchell \\
$\begin{array}{c}\text { Departamento de Ciência Política } \\
\text { Universidade de Chicago }\end{array}$ \\
\hline \hline
\end{tabular}
}

Resumo: Alguns estudiosos não examinam identidade racial de grupo entre os afro-brasileiros por causa da história do Brasil como uma nação racialmente mista. Dada a crescente força dos movimentos negros e a adoção de políticas raciais como ações afirmativas, que pressupõem a existência de grupos raciais, é necessário examinar se a identidade racial de grupo é saliente. Utilizando dados coletados em survey original de 2006, em Salvador e São Paulo, há evidências de que uma maioria esmagadora de afro. brasileiros se identifica como um grupo racial. Além disso, existe uma relação positiva e estatisticamente significante entre a identificação como um grupo racial e de voto para políticos negros em Salvador, porém não em São Paulo.

Palavras-chave: políticas raciais; opinião pública; identidade de grupo afro-brasileiro

Abstract: A number of scholars do not examine racial group identity among Afro-Brazilians because of Brazil's history as a racially mixed nation. Given the growing strength of the black movements and the enactment of racial policies such as affirmative action that presume the existence of racial groups it is necessary to examine if racial group identity is salient. Using original survey data collected in 2006 in Salvador and São Paulo, Brazil, there is evidence that an overwhelming majority of Afro-Brazilians in identify as a racial group. Furthermore, there is a positive and statistically significant relationship between identifying as a racial group and voting for black politicians in Salvador but not in São Paulo.

Keywords: racial politics; public opinion; afro-brazilian group identity

OPINIÃO PÚBLICA, Campinas, vol. 15, no 2, Novembro, 2009, p.273-305 
"Se alguém sofre preconceito racial, isso também me afeta. Temos empatia e, na verdade, estamos todos no mesmo barco. Aquilo que prejudica um (negro) também me prejudica. Precisamos nos unir para lutar juntos contra diversos tipos de preconceito." (Jovem afrobrasileiro, 27 anos, São Paulo, entrevistado pela autora)

"Eu acho interessante esse sentimento de fraternidade que os negros demonstram entre si. Acho que é bem forte. Não sei se o mesmo acontece com os brancos. Ao estudar a África, sinto como se tivesse nascido lá e vindo para o Brasil. É como se fôssemos todos irmãos. E se algo acontece com os negros, é mais um incentivo para que eu procure mudar o sistema." (Universitária afrobrasileira, 19 anos, Salvador, entrevistada pela autora)

"A negritude surgiu com Zumbi. Reconhecer que você é quem é significa lutar pela liberdade e por direitos iguais. Infelizmente, o Brasil é um país onde ainda há muita desigualdade. Ao reconhecer sua negritude, aceitar que você é negro, que você também é capaz de concluir a universidade, tornar-se professor, ser o que quer que você quiser, isso significa reconhecer sua negritude." (jovem afrobrasileiro, 26 anos, São Paulo, entrevistado pela autora)

Atualmente, um número crescente de jovens afrobrasileiros, especialmente aqueles com níveis mais altos de educação, reconhecem sua negritude e, de certa forma, identificam-se como um grupo racial negro, que enfrenta desafios como o racismo como grupo. Considerando mudanças recentes na política racial brasileira, tais como a implementação de ações afirmativas nas universidades e de uma lei federal determinando que escolas públicas ofereçam aulas de História Afrobrasileira, torna-se necessário examinar a identidade coletiva racial negra no Brasil.

Os movimentos negros brasileiros exigiram continuamente essas mudanças e também encorajaram os afrobrasileiros a assumirem sua negritude. Dados de estudos realizados em 2006 em Salvador e em São Paulo demonstram que há evidências de identificação como um grupo racial negro. Mas como se manifesta na escolha eleitoral essa identidade coletiva? Este artigo examina a relação entre a identificação como um grupo racial negro e o voto em políticos negros. Evidências demonstram que uma forma mais branda de identificação coletiva racial - tal como a convicção de que, independente da cor da pele, todos os afrobrasileiros são negros - é estatisticamente significante e positivamente associada ao voto em políticos negros. Uma forma mais forte de identificação coletiva racial, apurada 
como a conviç̧ão de que aquilo que afeta os negros afeta também os indivíduos afrobrasileiros, não é estatisticamente significante nas cidades mencionadas. Além disso, afrobrasileiros que se identificam como negros (pretos ou negros) tendem mais a votar em políticos negros do que aqueles que se definem por cores de pele mais claras. Portanto, a escolha de identificadores raciais e de cor não são decisões sem implicações, pelo contrário, influenciam as decisões políticas.

Uma lacuna considerável persiste na compreensão da política brasileira. Por um lado, estudiosos não encontram evidências de que a raça tenha impacto sobre a política no país (von METTENHEIM, 1986; HAGOPIAN, 1996; MAINWARING et al, 2000). Por outro lado, a política racial e o papel da raça na política brasileira vêm sendo estudados pelo menos desde a década de 1970 (de SOUZA, 1971; MITCHELL, 1977, 2007; SOARES e SILVA, 1987; VALENTE, 1986; CASTRO, 1993; HANCHARD, 1994; OLIVERA, 1997, 2007; JOHNSON, 1996, 2006; NOBLES, 2000, dos SANTOS, 2000, GUIMARÃES, 2001). Com a esperança de ampliar o conhecimento sobre o importante papel desempenhado pela raça na política brasileira, minha pesquisa procura somar-se a esse grande número de trabalhos. A política racial brasileira mudou consideravelmente desde a década de 1980. Por isso, estudiosos da política brasileira deveriam levar em conta as implicações de tais mudanças ao abordar o universo político no país. Os estudos acadêmicos devem refletir sobre os estudos sobre raça já realizados. A compreensão insuficiente do fenômeno deve-se à falta de conhecimento sobre os movimentos negros no país, à pesquisa obsoleta sobre as políticas raciais e à ênfase sobre opiniões políticas de brasileiros brancos e afrobrasileiros. Examinar opiniões políticas entre grupos como brasileiros brancos e afrobrasileiros, em lugar de examinar as opiniões políticas entre os afrobrasileiros, acaba por mascarar diferenças e semelhanças entre os próprios afrobrasileiros.

Muitos estudiosos da política brasileira não encontram qualquer diferença em termos de opinião política entre afrobrasileiros e brasileiros brancos (MAINWARING et al, 2000; HAGOPIAN, 1996; von METTEINHEIM, 1986). Trabalhos decisivos que efetivamente examinaram a raça na política brasileira enfocaram a mobilização dos afrobrasileiros, políticos afrobrasileiros ou atitudes raciais entre afrobrasileiros. Hanchard (1994) teve êxito em destacar os esforços de ativistas do movimento negro desde a década de 1930 até os anos oitenta. Ele também investiga o papel que a hegemonia racial desempenhou ao impedir uma mobilização negra mais ampla. Os trabalhos de Johnson $(1996,2006)$ examinam a representação afrobrasileira no Congresso e o papel desempenhado por políticos afrobrasileiros na promoção de políticas raciais no âmbito nacional. Também o trabalho acadêmico de Mitchell $(1977,2000)$ destaca as atitudes raciais de ativistas do movimento negro e de afrobrasileiros associados a organizações envolvidas com o movimento negro. Esses estudiosos fizeram importantes 
contribuições para o estudo da política racial no Brazil, mas tendem a concentrar-se sobre as elites afrobrasileiras, tais como ativistas do movimento negro e políticos afrobrasileiros, em detrimento do eleitorado afrobrasileiro.

Desde os anos setenta, diversos acadêmicos brasileiros realizaram pesquisas sobre o voto étnico de afrobrasileiros. De acordo com esses trabalhos, não existe algo como um voto étnico, mas sim alguns partidos políticos que o cultivam, que a raça tem um papel nas campanhas políticas e que existem diferenças de opinião política entre os afrobrasileiros. Souza (1971) apóia-se em dados da eleição presidencial de 1960 para investigar o voto étnico, constatando que, em comparação com os brasileiros brancos, uma ampla maioria dos afrobrasileiros, independente de classe social, apoiou o Partido Trabalhista Brasileiro (PTB). Ele atribui essa diferença ao fato de que, durante o período em que Getúlio Vargas esteve no poder, alguns afrobrasileiros foram capazes de ascender social e economicamente. Consequentemente, afrobrasileiros de classe média seguiram apoiando o partido de oposição ao qual Vargas pertencia. Afrobrasileiros pobres apoiavam o PTB porque esse se apresentava como o partido dos pobres. Apesar disso, Souza não encontra qualquer diferença significante entre eleitores brancos e afrobrasileiros em termos de participação eleitoral ou interesses políticos.

Enfocando somente candidatos e eleitores afrobrasileiros, Ana Valente (1986) examina as eleições de 1982 em São Paulo. Partidos como o Partido Democrático Trabalhista (PDT), o Partido do Movimento Democrático Brasileiro (PMDB) e o Partido dos Trabalhadores (PT), todos de esquerda, apoiaram candidatos afrobrasileiros e promoveram demandas de grupos minoritários. Ativistas do movimento negro encorajaram afrobrasileiros a votar em candidatos negros. Apesar dos esforços em prol de um voto étnico, dos 54 candidatos afrobrasileiros disputando a eleição, apenas dois foram eleitos, sendo que nenhum dos dois era afiliado ao movimento negro ou discutiu abertamente questões raciais. Os dados levantados por Valente revelaram que a maioria dos eleitores afrobrasileiros não estava familiarizada com os candidatos negros que concorreram e não demonstraram interesse por suas afiliações raciais. Por tais razões, não votaram neles. Diferenças ideológicas no interior do movimento negro também contribuiram para que não conquistassem votos entre o eleitorado afrobrasileiro. Valente reconhece que os ativistas do movimento negro se precipitaram em sua expectativa por um voto étnico. Sales Augusto dos Santos (2000) investiga por que deputados federais afrobrasileiros jamais formaram uma bancada dedicada a questões raciais, e conclui que isso não ocorreu porque os deputados acreditavam que isso acabaria por afastar os eleitores, o que também indica que não acreditavam que um voto étnico fosse capaz de garantir-Ihes um mandato.

Diferente do que ocorreu nas eleições de 1982 em São Paulo, com apenas 
dois afrobrasileiros eleitos, Cloves Oliveira (1997) constatou que um elevado número de candidatos afrobrasileiros foi eleito em Salvador, na Bahia. Nas eleições de 1992, os candidatos afrobrasileiros eleitos para a câmara de vereadores tinham origens na classe trabalhadora, em contraste com os candidatos brancos eleitos, que tinham origens nas classes média e alta. Ademais, comparando os resultados das eleições de 1992 e de 1998, constata-se que o número de vereadores afrobrasileiros eleitos subiu de 11 para 34\% da bancada, devido a um aumento no número de vereadores oriundos da classe trabalhadora. Oliveira acredita que uma mudança no recrutamento político pelos partidos contribuiu para esse aumento. No entanto, afrobrasileiros continuam sub-representados em Salvador, especialmente ao se considerar que cerca de $70 \%$ da população são afrodescendentes.

Soares e Silva (1987) analisam a eleição de Leonel Brizola em 1982 para o governo do estado do Rio de Janeiro. AEmbora seu foco sejam os efeitos da urbanização, da classe social e da organização partidária na composição do voto em favor de Brizola em vários dos municípios fluminenses, os autores também mostram interesse em fatores associados à questão racial, e constatam que, quanto maior a proporção de não-brancos em um dado município, maior a votação recebida por Brizola. Morenos tendiam mais a votar em Brizola do que brancos e negros. Afrobrasileiros que se identificam como pardos podem ter uma cor de pele mais clara ou mais escura. Telles (2004) sustenta que afrobrasileiros de pele escura que se identificam como morenos possivelmente procuram expressar por meio dessa identificação uma forma de branqueamento. Ele acredita que se trata de um termo ambivalente, que permite às pessoas que não são consideradas brancas evitarem as categorias não-brancas mais estigmatizadas (TELLES, 2004, p.98). Soares e Silva sugerem três possíveis razões para que os negros não tivessem apoiado Brizola tanto quanto os pardos. Uma delas se refere ao fato de Brizola ter feito um apelo explícito ao socialismo moreno, na tentativa de atrair votos afrobrasileiros. Entretanto, é também possível que Brizola tenha afastado os eleitores negros ao apelar para um socialismo moreno e não para um socialismo negro. A segunda razão diz respeito ao fato de que os negros fluminenses vivem predominantemente fora da área metropolitana da cidade do Rio, em áreas onde a organização do partido não era muito forte. Finalmente, o analfabetismo pode ter tido um papel em termos de acesso dos eleitores às mensagens políticas e, dentre todos os grupos de cor, os negros são os que têm a maior taxa de analfabetismo.

Cloves Oliveira (2007) realizou o trabalho acadêmico de maior envergadura e alcance dentre aqueles que investigam o papel que a mídia desempenhou nas campanhas eleitorais de Benedita da Silva no Rio de Janeiro e de Celso Pitta em São Paulo. Da Silva concorreu para a prefeitura do Rio em 1992 e perdeu. Pitta, para a prefeitura de São Paulo em 1996 e venceu. Ambos são afrobrasileiros, mas da Silva é conhecida por abordar questões relacionadas a raça, gênero e classe e é 
afiliada ao Partido dos Trabalhadores (PT), de perfil progressista. Pitta, por outro lado, evitou abordar questões raciais e pertencia a um partido político conservador, - Partido Progressista Brasileiro (PPB). É evidente que a raça teve um papel importante no modo como a mídia retratou ambos os candidatos. Seu estudo também procurou avaliar como mensagens explicitamente raciais foram utilizadas por uma série de candidatos na tentativa de galvanizar o apoio de eleitores afrobrasileiros. A atenção de Oliveira está mais voltada aos políticos do que aos eleitores afrobrasileiros. Porém, seu trabalho é importante na definição da relevância da raça na política eleitoral brasileira.

Todos os estudos mencionados demonstram a importância da raça na política eleitoral. Para além dos já indicados, Antonio Sergio Guimarães (2001) inclui os seguintes autores entre aqueles que contribuíram para a discussão sobre raça e política: Bolivar Lamounier (1968), Reginaldo Prandi (1996) e Gilberto Freyre. Este é incluído por conta de sua afirmação de que afrobrasileiros preferem líderes populistas. Freyre atribui tal tendência com base na relação paternalista oriunda do regime escravista. Guimarães também menciona a pesquisa de Mônica Castro (1993) sobre o voto negro, na qual ela constata que afrobrasileiros de poucos recursos econômicos abstêm-se de votar ou invalidam seus votos, enquanto afrobrasileiros mais abastados favorecem políticos de esquerda. Castro não encontra qualquer diferença significativa entre o comportamento eleitoral de negros e pardos.

A tônica geral da literatura existente sobre o tema é que não há diferença em termos de opinião política entre brancos e afrobrasileiros. Alguns autores oferecem evidências de que o voto étnico de afrobrasileiros na realidade existe, apesar de a eleição de um candidato afrobrasileiro ainda representar um desafio. Considerando as entrevistas realizadas por Santos (2000), parece que alguns políticos afrobrasileiros não acreditam que seja viável serem eleitos com base no voto étnico.

Aparentemente, políticos afrobrasileiros que pretendem obter um mandato evitam abordar explicitamente temas raciais, temendo que isso possa afastar eleitores que não consideram tais temas relevantes. Dado o fato de que políticas de ação afirmativa começaram a ser implementadas em 2001 e que a discriminação racial é discutida mais abertamente na política brasileira, cabe avaliar se as atitudes e opiniões raciais também se moveram na mesma direção. Se os afrobrasileiros veem sua situação socioeconomica como resultante de sua classe e de sua raça, é plausível que candidatos que abordam questões raciais atualmente tenham maior apelo do que no passado.

Cabe mencionar que Soares e Silva (1987) analisaram negros e pardos como grupos de cor independentes um do outro, em lugar de tratá-los como um único grupo. Autores que avaliaram as opiniões políticas de afrobrasileiros em 
comparação com as dos eurobrasileiros não encontraram diferenças significativas (MAINWARING apud MIDDLEBROOK, 2000, p.202). Tais resultados se devem ao fato de que os autores examinaram a dinâmica intergrupo, ao invés da dinâmica intragrupo dos afrobrasileiros. Um estudo comparativo entre brasileiros brancos e afrobrasileiros pode ocultar diferenças entre os próprios afrobrasileiros que optam por identidades raciais variadas. A maior parte dos estudos científicos combina os grupos pardo e preto, enquanto a maioria dos afrobrasileiros em todo o país opta preferencialmente por uma identidade parda. A opção por uma identidade combinada parda e negra pode estar associada a variações mais significativas em termos de preferências por candidatos e opiniões políticas do que a opção por uma identidade integralmente negra. À medida em que cada vez mais afrobrasileiros optam por uma identidade negra, é possível que se produza uma diferença mais significativa em termos de opinião política entre afrobrasileiros e brancos. Dinâmicas intragrupos são importantes no exame da política racial porque permitem destacar similaridades e diferenças no interior do eleitorado afrobrasileiro ao tratá-lo como a unidade de análise. Isso é determinante para o estudo da política racial.

Veículos tais como o jornal Folha de São Paulo e a imprensa ligada ao movimento negro discutiram as eleições presidenciais de 2006 em termos de raça e, sob muitos aspectos, pressupuseram a ocorrência do voto étnico. A ideia de voto étnico no Brasil era algo inédito e ainda não era levada a sério, a não ser por ativistas do movimento negro. $O$ fato de que os principais órgãos da imprensa brasileira tenham passado a considerar que um voto étnico poderia determinar o resultado das eleições presidenciais deixa claro que o Brasil é um país que deveria ser seriamente considerado por estudiosos da política étnica. Ainda mais importante, considerando que políticas de ação afirmativa foram implementadas a partir de 2001 e que a discriminação racial é discutida mais abertamente na política nacional, vale a pena investigar se as atitudes e opiniões relativas a questões raciais também mudaram na mesma direção. Além disso, brasileiros negros e pardos atualmente ultrapassam em número os brasileiros broncos, e esse aumento se deve ao maior número de afrobrasileiros que passaram a identificar-se como negros ou pretos (WERNECK, 2008).

A política racial no Brasil mudou dramaticamente no âmbito nacional, onde anteriormente temas raciais eram muito raramente discutidos e se procurava sustentar a força do mito de uma democracia racial. Assim, denúncias de racismo eram rapidamente desconsideradas. Apesar de constantes denúncias de racismo feitas por ativistas do movimento negro desde pelo menos os anos trinta, o impacto de suas organizações e iniciativas finalmente passaram a exercer influência sobre a formulação de políticas públicas. Isso começou já na década de 1990, com o reconhecimento público do presidente Fernando Henrique Cardoso de que o 
racismo efetivamente existe na sociedade brasileira e seguiu com a indicação pelo presidente Lula de diversos afrobrasileiros para altos cargos na administração federal. Além disso, ações afirmativas foram implementadas, que, por definição, diferenciam os cidadãos de acordo com grupos raciais e reconhecem a necessidade de tratamentos preferenciais para grupos específicos.

Considerando a mudança radical na política racial - da crença predominante na democracia racial, que sustentava que a discriminação racial não existia no país, em razão de sua composição demográfico-racial mista, até o reconhecimento oficial do racismo e a implementação de programas de ação afirmativa nas universidades -, é necessário revisitar a questão sobre a existência ou não de uma identidade coletiva entre os afrobrasileiros e, caso exista, sobre a medida em que ela afeta a escolha eleitoral.

\section{Identidade coletiva racial negra e suas implicações políticas}

Apesar da mobilização negra que ocorre por toda a América Latina (ANDREWS, 2001), não é claro que os afrobrasileiros se veem como um grupo racial negro. Robin Sheriff (2001) constatou que afrobrasileiros pobres e trabalhadores no Rio de Janeiro admitem pertencer à raça negra. Se a identidade coletiva negra existe, quais são suas implicações políticas? A questão é se a identidade coletiva existe entre os brasileiros e quão influente ela é na preferência por um candidato. Além disso, que papel a identificação por cor desempenha nessa preferência? É possível que o ativismo do movimento negro, além do debate público sobre a desigualdade racial e a promoção de políticas públicas raciais tenham influenciado a maneira como eles se identificam enquanto grupo. Por conta disso, é esperado que afrobrasileiros que se identificam como parte de um grupo racial negro apóiem mais os políticos negros do que aqueles que não se identificam como tal. Essa hipótese é testada com questões que medem identidades coletivas fortes e fracas e uma questão relacionada ao voto em prol de um político negro.

\section{Método}

Em 2006, foi mobilizada uma equipe de estudantes universitários em Salvador e São Paulo para entrevistar pessoalmente eleitores afrobrasileiros. Todos os entrevistadores receberam um treinamento sobre como deveriam ser conduzidas as entrevistas. Professores da Universidade Federal da Bahia e da Universidade de São Paulo auxiliaram na seleção dos bairros das respectivas cidades e recomendaram os estudantes de graduação. A seleção de bairros levou em conta a presença de afrobrasileiros de diferentes níveis socioeconomicos neles. Os bairros selecionados em Salvador foram: Federação, Peri- Peri e Itapuã. Federação é 
bastante heterogêneo em termos socioeconomicos. Nesse bairro, que possui tanto vizinhanças de classe média como também habitações de uma população de renda bastante baixa, está localizada parte do campus da UFBA, considerada uma universidade pública de prestígio. Itapuã também é socioeconomicamente diversificado, mas abriga um alto número proporcional de famílias de baixa renda. Em São Paulo, as entrevistas foram conduzidas nos bairros de Cidade Tiradentes, Casa Verde, Brasilândia, Campo Limpo e Capão Redondo. Cidade Tiradentes é uma área que abriga uma população de baixa renda no extremo leste da cidade, sendo bem conhecida por sediar um grande número de organizações sem fins lucrativos. Casa Verde se situa no nordeste da cidade e tem uma população predominante de classe média, enquanto o Campo Limpo, localizado a sudoeste, é conhecido por suas fortes clivagens sociais. Favelas estendem-se ao largo de condomínios de classe média e alta.

Para as duas cidades foram elaboradas amostras aleatórias sistemáticas. Obtivemos mapas dos bairros junto ao Instituto Brasileiro de Geografia e Estatística (IBGE) e, a partir deles, ruas foram selecionadas aleatoriamente. Cada um dos estudantes foi designado para trabalhar em pelo menos dois dos bairros mencionados, onde também aplicaram o método sistemático para realizar as entrevistas em uma de cada cinco casas; no caso de uma rua não possuir um número razoável de casas, uma de cada três. Os entrevistadores explicavam aos possíveis entrevistados que não era necessário fornecer qualquer informação pessoal e que nenhuma informação capaz de identificá-los seria registrada. Os estudantes foram instruídos a entrevistarem somente pessoas de ascendência africana. Ao dirigir-se às casas, explicavam aos moradores que estavam realizando entrevistas com afrodescendentes. Caso o entrevistador fosse recebido por uma pessoa que considerasse branca, deveria perguntar se haveria na casa alguém de ascendência africana. Assim, mesmo que o entrevistador classificasse uma pessoa como branca, a entrevista era realizada sempre que o morador se identificasse como afrodescendente. Por outro lado, houve casos em que o entrevistador classificou o morador como negro ou pardo, mas esse se identificava como pertencente a outra categoria de cor. Ao analisar as menções à cor nas entrevistas, adotamos como índice de identificação racial a resposta dos entrevistados à questão aberta sobre sua cor. Para o estudo, foram utilizadas somente as entrevistas nas quais o entrevistado tinha idade para votar. No total, foram realizadas 674 entrevistas em Salvador e São Paulo e o índice de aproveitamento foi de $99 \%$. 


\section{Identificação pela cor e negritude}

Definimos a identificação pela raça ou pela cor no Brasil como a autoatribuição de uma categoria racial ou de cor com a consciência da prevalência de uma hierarquia que ordena socialmente as cores. No topo está a cor branca, no meio, a parda e, na base, a negra. Conforme sugerido por Rogers Brubaker e Frederick Cooper (2000), utilizamos o termo identificação em lugar de identidade, porque ele parece capaz de levar em conta o fato de que as identidades não se revelam constantes ao longo do tempo. Apesar de os brasileiros não necessariamente concordarem com a hierarquia das cores, os cidadãos são conscientes de sua existência. Diversas tonalidades mestiças se distribuem ao longo desse espectro. Estão associadas às cores conotações transmitidas por meio do humor e de expressões populares que valorizam o branco como algo benigno e o negro como algo daninho. A identificação racial dos indivíduos pode variar de acordo com a circunstância social na qual se encontram. Além disso, os cidadãos, por vezes manipulam sua identificação para alterar sua posição no espectro das cores.

Raça é normalmente vista como algo biológico, enquanto a cor é composta pela aparência física e pela posição social. Por exemplo, a terminologia da cor inclui categorias como preto, pardo, moreno, moreno claro e branco. No entanto, o termo politicamente forte, negro, é uma categoria racial com a qual afrobrasileiros de todas as cores podem se identificar. Ela foi incialmente promovida por ativistas do movimento negro, mas hoje é utilizada mesmo pelos grandes órgãos de imprensa ao veicular informações e dados relacionados aos afrobrasileiros e, quando utilizada, refere-se tanto a pretos como pardos. Jornais de grande circulação, como a Folha de São Paulo, chegaram a discutir a possibilidade de utilizar o termo negro durante a eleição presidencial de 2006. Cabe ressaltar novamente que a categoria negro é fundamentalmente uma categoria política, que pode ser assumida por afrobrasileiros de qualquer cor, sendo igualmente um termo que os ativistas do movimento negro procuram promover amplamente entre a população afrobrasileira. Em todo o país, a maioria dos afrobrasileiros se classifica como pardo. No censo de $2000,45 \%$ da população total se identificaram como brancos, 39\% como pardos, $6 \%$ como pretos e menos de $1 \%$ se identificou como amarelo ou indígena, compondo as cinco categorias utilizadas pelo censo. Em Salvador, 22\% da população se consideram brancos, $46 \%$ pardos e $20 \%$ negros. Em números absolutos, São Paulo tem mais habitantes que adotam uma identidade negra. Em São Paulo, 872.609 afrobrasileiros se identificaram como pretos, enquanto apenas 605.199 afrobrasileiros em Salvador o fizeram. Semelhante à teoria de Mark Sawyer (2006) dos ciclos raciais, sempre que o estado recorre à cultura negra em períodos de retração econômica, acredito que os afrobrasileiros adotem uma identidade 
negra de acordo com o contexto e sempre que ela seja benéfica. A ação afirmativa oferece um forte incentivo para a adoção de uma identidade negra ou parda, assegurando a oportunidade de ascensão social através da educação. Assim, é provável que afrobrasileiros que adotem uma identidade negra sejam beneficiados por ela. Também é possível que tais pessoas adquiram uma incomensurável autoconsciência, permitindo que tirem proveito econômico de sua identidade no Mercado, a despeito do racismo persistente na sociedade brasileira. Afrobrasileiros com empregos menos prestigiosos não se deparam com o mesmo tipo de racismo enfrentado por aqueles que possuem empregos de maior prestígio ou que se encontram em posições de autoridade (ANDREWS, 1991, TWINE, 1998, SHERIFF, 2001). Justamente em razão de oportunidades, prestígio e riqueza serem codificados como domínio dos brancos na sociedade brasileira, os afrobrasileiros racionalmente optam por uma identidade não-negra, na tentativa de obter os privilégios normalmente associados aos brancos.

\section{Dados descritivos da amostra}

Em Salvador, $52 \%$ dos entrevistados eram homens e $48 \%$ mulheres, enquanto em São Paulo 43\% eram homens e 57\% mulheres. Em ambas as cidades, a idade média foi de 33 anos, variando dos 17 aos 67 anos em Salvador e dos 16 aos 83 em São Paulo. Uma questão aberta e outra fechada questionaram os entrevistados a respeito de sua cor. Na questão aberta, eles podiam identificar-se pela cor que preferissem, sem que quaisquer opções fossem apresentadas. $\mathrm{Na}$ questão fechada, pedia-se que optassem por uma das categorias de cor do censo. As categorias empregadas pelo censo de 2000 foram: branco, pardo, preto, amarelo e indígena. (amarelo se refere a pessoas de ascendência asiática).

Os resultados mostram que, em ambas as cidades, um número maior de afrobrasileiros adotavam uma categoria de cor ou raça parda na questão aberta do que o número daquele que eram assim classificados pelos entrevistadores. Em Salvador, os entrevistadores classificaram 102 entrevistados como pardos, enquanto 121 deles se autoclassificaram assim (mulato, moreno, pardo, moreno claro, marrom). Em São Paulo, os entrevistadores classificaram 119 dos entrevistados como pardos, enquanto 143 deles se autoclassificaram assim (mulato, moreno, pardo, moreno claro, moreno escuro, moreno jambo, marrom). Consideramos todas essas variantes como pardos, de modo a poder comparar respostas à questão aberta com os resultados da questão fechada. A Tabela 1 apresenta os resultados em números absolutos. 
Tabela 1

Número de afrobrasileiros entrevistados que se autoidentificaram de acordo com categorias do censo e de acordo com categorias autoclassificatórias e número de entrevistados classificados de acordo com categorias do censo pelos entrevistadores

\begin{tabular}{|c|c|c|c|c|c|}
\hline \multicolumn{6}{|c|}{ Salvador } \\
\hline \multicolumn{2}{|c|}{$\begin{array}{l}\text { Identificação do } \\
\text { entrevistado de } \\
\text { acordo com o censo }\end{array}$} & \multicolumn{2}{|c|}{$\begin{array}{c}\text { Autoclassificação do entrevistado em resposta à } \\
\text { questão aberta }\end{array}$} & \multicolumn{2}{|c|}{$\begin{array}{l}\text { Categoria de cor na } \\
\text { classificação pelo } \\
\text { entrevistador }\end{array}$} \\
\hline Branco & 12 & Branco & 8 & Branco & 2 \\
\hline Preto & 208 & Preto (Negro, "negão", preto) & 210 & Preto & 230 \\
\hline Pardo & 104 & $\begin{array}{l}\text { Pardo (Mulato, moreno, pardo, moreno } \\
\text { claro, marrom) }\end{array}$ & 121 & Pardo & 102 \\
\hline Outro & 6 & Outro & & Outro & 0 \\
\hline \multicolumn{6}{|c|}{ São Paulo } \\
\hline \multicolumn{2}{|c|}{ Categoria do censo } & \multicolumn{2}{|l|}{ Categoria na questão aberta } & \multicolumn{2}{|c|}{$\begin{array}{l}\text { Classificação pelo } \\
\text { entrevistador }\end{array}$} \\
\hline Branco & 21 & Branco & 20 & Branco & 4 \\
\hline Preto & 141 & Preto (Negro, "negão", preto) & 150 & Preto & 191 \\
\hline Pardo & 131 & $\begin{array}{l}\text { Pardo (Mulato, moreno, pardo, moreno } \\
\text { claro, moreno escuro, moreno jambo, } \\
\text { marrom) }\end{array}$ & 143 & Pardo & 119 \\
\hline Outro & 0 & Outro & 3 & Outro & 3 \\
\hline
\end{tabular}

Em toda a amostra, a categoria de cor ou raça com a qual a maioria dos afrobrasileiros se identifica é preto (negro e preto). Considerando as categorias apresentadas em resposta à questão aberta, a amostragem dos afrobrasileiros em Salvador é composta por $2 \%$ que se identificam como brancos, $62 \%$ como negros (preto, negro, "negão") e 36\% como pardos (mulato, moreno, pardo, moreno claro, marrom), enquanto em São Paulo $6 \%$ se identificam como brancos, $47 \%$ como negros (preto, negro, "negão"), $45 \%$ como pardos (mulato, moreno, pardo, moreno claro, moreno escuro, moreno jambo e marrom) e $2 \%$ adotam outra categoria. $\mathrm{Na}$ análise que fizemos, a categoria aberta de cor é levada em conta porque consiste em uma escolha livre por parte dos entrevistados, em oposição à classificação estrita do censo. Notamos que essas são as categorias que os entrevistados elegeram para se identificarem perante os entrevistadores e, possivelmente, em outras situações da vida cotidiana, uma vez que categorias de identificação pela cor podem mudar a cada minuto, dependendo da situação social de cada pessoa.

É interessante notar que em ambas as cidades, um total de trinta e três afrobrasileiros entrevistados identificaram-se como brancos ao optarem por uma das categorias do censo. Porém, os entrevistadores classificaram apenas seis dos entrevistados como brancos. Nenhum daqueles que se autoidentificaram como brancos foi classificado como tal pelos entrevistadores. Em Salvador, doze entrevistados identificaram-se como brancos e em São Paulo, 21, o que não surpreende, considerando os privilégios associados à cor branca no Brasil 
(SHERIFF, 2001; TWINE, 1998). Em Salvador, metade dos entrevistados que se autoidentificaram como brancos eram mulheres. Em São Paulo, a relação foi de 19 mulheres para 14 homens. A idade média dos entrevistados que se identificaram como brancos em ambas as cidades foi de 37 anos (28 em Salvador e 43 em São Paulo). Assim, os afrobrasileiros que se identificaram como brancos em Salvador eram em média 15 anos mais jovens do que os de São Paulo. Em Salvador, 75\% dos afrobrasileiros que se identificaram como brancos pertenciam às duas camadas de renda familiar mais baixa. Quatro dos entrevistados tinham uma renda familiar de menos de $\cup \$ 350$ mensais, enquanto outros cinco tinham uma renda familiar mensal entre $\cup \$ 350$ e $\bigcup \$ 875$ e três não responderam a questão relativa à renda. Em São Paulo, a tendência é similar, pois $67 \%$ os entrevistados que se identificaram como brancos pertencem às duas camadas de renda mais baixa, oito deles tendo uma renda familiar mensal de menos de $U \$ 350$, seis na faixa entre U\$350 e U\$875 e quatro na faixa entre U\$1750 e U\$3500. Em São Paulo, os três entrevistados situados na camada de renda mais alta, vivem no bairro da Casa Verde, que abriga em sua maioria famílias de classe média. Quatro dos entrevistados estavam na terceira camada mais alta de renda, dois deles vivendo em Capão Redondo, um em Brasilândia e um em Cidade Tiradentes. Por outro lado, dos 14 entrevistados situados nas duas camadas mais baixas de renda, três eram de Brasilândia, quatro de Cidade Tiradentes, três da Casa Verde, três do Campo Limpo e um do Capão Redondo. Isso denota uma distribuição equilibrada dos entrevistados mais pobres entre os que se identificam como brancos. Em Salvador, todos os entrevistados que se identificaram como brancos e forneceram informações sobre sua renda pertenciam às duas camadas mais baixas de renda, sendo que sete deles viviam em Peri-peri, um bairro predominantemente de baixa renda, um em Itapuão e um em Federação. O mais interessante nesses resultados é o fato de que, em ambas as cidades, a maioria dos entrevistados que se identificaram como brancos pertencem às camadas mais baixas de renda. Tanto o velho provérbio segundo o qual o dinheiro embranquece como o lugar-comum que pressupõe que, depois de ganhar muito dinheiro, os afrobrasileiros passam a se considerar brancos não são inteiramente plausíveis. Como a pesquisa etnográfica demonstra, afrobrasileiros de baixa renda também aspiram ao branqueamento (SHERIFF, 2001; TWINE, 1998), e os dados desta pesquisa demonstram. 


\section{Status socioeconômico e bairros}

Avaliando indicadores de status socioeconômico, tais como níveis de educação e renda familiar, percebemos que todos os bairros selecionados são bastante diversificados. Porém, alguns apresentam níveis mais altos de escolarização e outros possuem níveis mais altos de renda. Casa Verde, em São Paulo, tem o maior percentual de entrevistados com 15 ou mais anos de educação formal (29\%), enquanto Campo Limpo, também em São Paulo, tem a maior proporção de entrevistados com apenas um a três anos de educação formal (23\%). Em Itapuã, um dos bairros de Salvador, $26 \%$ dos entrevistados tinham apenas de quatro a sete anos de escolarização, enquanto em Brasilândia, na cidade de São Paulo, 25\% dos entrevistados tinham esse mesmo nível de escolaridade. Em todos os bairros, a maioria dos entrevistados se situa na faixa de 11 a 14 anos de escolaridade.

No que diz respeito à renda, impressionantes $73 \%$ dos entrevistados que moravam em Cidade Tiradentes (São Paulo) situavam-se nas duas camadas mais altas de renda. Da mesma maneira, 59\% estavam nas duas faixas mais altas de escolaridade. Em Federação (Salvador), 27\% dos entrevistados situavam-se nas duas faixas mais altas de renda. Nesse quesito, essa foi a proporção mais alta entre todos os bairros de Salvador. Em Brasilândia (São Paulo), 10\% dos entrevistados não tinham qualquer renda familiar. Entretanto, o bairro com a maior parcela de entrevistados com renda familiar menor do que U\$350 mensais foi Itapuã, em (Salvador). Em São Paulo, entre todos os bairros, Campo Limpo teve o percentual mais alto de entrevistados com renda familiar mensal menor do que U\$350. Esses dados demonstram que, por conta de várias semelhanças, é possível fazer comparações entre os bairros de Salvador de São Paulo. 
Tabela 2

Anos de escolaridade, por bairro (\%)

\begin{tabular}{|l|l|l|l|l|l|l|}
\hline Bairro Escolaridade & $\begin{array}{l}1 \cdot 3 \\
\text { anos }\end{array}$ & $4 \cdot 7$ anos & $8 \cdot 10$ anos & $\begin{array}{l}11 \cdot 14 \\
\text { anos }\end{array}$ & $15+$ anos & Total \\
\hline Federação & 0 & 17 & 32 & 37 & 15 & 100 \\
\hline Itapuã & 0 & 26 & 26 & 41 & 17 & 100 \\
\hline Periperi & 1 & 21 & 30 & 38 & 10 & 100 \\
\hline Brasilândia & 9 & 25 & 18 & 46 & 3 & 100 \\
\hline $\begin{array}{l}\text { Cidade } \\
\text { Tiradentes }\end{array}$ & 2 & 15 & 24 & 43 & 16 & 100 \\
\hline Casa Verde & 11 & 17 & 21 & 22 & 29 & 100 \\
\hline Campo Limpo & 23 & 9 & 15 & 38 & 15 & 100 \\
\hline Capão Redondo & 0 & 0 & 0 & 91 & 9 & 100 \\
\hline
\end{tabular}

Tabela 3

Renda familiar mensal (em dólares), por bairro (\%)

\begin{tabular}{|c|c|c|c|c|c|c|}
\hline Bairro & $\begin{array}{l}\text { Sem } \\
\text { renda }\end{array}$ & $\begin{array}{c}\text { Menos de } \\
\$ 350\end{array}$ & $\begin{array}{l}\$ 350 \\
\$ 875\end{array}$ & $\begin{array}{l}\$ 875 \\
\$ 1750\end{array}$ & $\begin{array}{l}\$ 1750 \\
\$ 3500\end{array}$ & Total \\
\hline Federação & 2 & 28 & 43 & 23 & 4 & 100 \\
\hline Itapuã & 2 & 50 & 43 & 5 & 0 & 100 \\
\hline Periperi & 3 & 40 & 45 & 10 & 2 & 100 \\
\hline Brasilândia & 10 & 30 & 46 & 13 & 1 & 100 \\
\hline $\begin{array}{l}\text { Cidade } \\
\text { Tiradentes }\end{array}$ & 0 & 0 & 27 & 53 & 20 & 100 \\
\hline Casa Verde & 4 & 21 & 44 & 23 & 8 & 100 \\
\hline Campo Limpo & 0 & 43 & 40 & 17 & 0 & 100 \\
\hline $\begin{array}{l}\text { Capão } \\
\text { Redondo }\end{array}$ & 4 & 0 & 39 & 52 & 4 & 100 \\
\hline
\end{tabular}

\section{Viés seletivo}

Em âmbito nacional, a maioria dos afrobrasileiros se identificam como pardos, embora a maioria em nossa amostragem tenha se identificado como negros. No censo de 2000, em Salvador, $66 \%$ da população se consideravam pretos ou pardos. Em São Paulo, apenas $30 \%$ se consideravam pretos ou pardos. Utilizando dados do censo, é impossível verificar quantos afrobrasileiros identificaram-se como brancos. Para o propósito de comparar os dados levantados 
em nossa amostragem com os dados do censo, adicionamos os números de pretos e pardos do censo para calcular o percentual de afrobrasileiros que se consideram pretos ou pardos em cada cidade. Entre os afrobrasileiros (pretos e pardos) de Salvador, $74 \%$ consideram-se pardos e $26 \%$ pretos $^{1}$. Esses dados apontam que a amostra que obtivemos em Salvador tem um viés de seleção, na medida em que não representa o percentual real de como se identifica a maioria dos afrobrasileiros. Nela, uma ampla maioria (65\%) se identificou como negra (preto ou negro), enquanto apenas $26 \%$ dos afrobrasileiros se identificaram como negros no censo de 2000. Uma estimativa aproximada da identificação de afrobrasileiros em São Paulo, a partir do censo de 2000 , apresenta $15 \%$ que se identificam como pretos e $85 \%$ como pardos. Em nossa amostragem, $47 \%$ dos afrobrasileiros de São Paulo identificaram-se como negros (preto ou negro). Essas distorções podem ser explicadas pelo fato de que os bairros foram selecionados em áreas onde há maior presença de afrobrasileiros. Entretanto, os dados levantados revelam claras tendências nos bairros selecionados em cada uma das cidades. Como o survey foi feito com base em uma amostra aleatória, possibilita seu uso em análises estatísticas.

No que se refere à demografia racial, diferenças entre dados de amostragem e dados censitários também podem ser explicados, nesse caso, pelo fato de amostra ser relativamente recente e, a esse respeito, Livio Sansone (2003) já havia demonstrado que afrobrasileiros mais jovens tendem a identificar-se como negros. Stanley Bailey e Edward Telles (2006) constataram que idade e educação afetam positivamente o uso do termo negro. Ambos os estudos revelaram como pessoas mais jovens têm uma probabilidade maior de optarem por essa categoria racial do que pessoas mais velhas, e revelaram também que pessoas com níveis mais altos de escolaridade tendem mais a optar pela categoria negro do que pela categoria moreno (BAILEY e TELLES, 2006).

\section{Identidade coletiva racial negra}

O conceito de utilidade heurística negra desenvolvido e aplicado por Dawson (1994) para compreender a identidade coletiva racial negra e as preferências políticas de afrodescendentes nos Estados Unidos, pode também ser útil no caso brasileiro. Esse conceito se apóia em um conjunto de experiências históricas semelhantes vividas como um grupo e em noções de coletividade reforçadas pela ação de instituições (DAWSON, 2001). Ao mesmo tempo em que se percebe que o conceito de Dawson se apóia claramente nas circunstâncias históricas que forjaram uma forte identidade coletiva entre os afroamericanos, ele pode ajudar a entender o

${ }^{1}$ Cf. IBGE: <http://www.sidra.ibge.gov.br/bda/tabela/protabl.asp?z=cd\&o=7\&i=P> 
efeito que mudanças recentes na política racial brasileira poderão ter na formação de identidades coletivas no país. Estudiosos já documentaram que os afrobrasileiros adotam algumas noções de identificação racial. Robin Sheriff (2001) percebeu que, na comunidade carioca onde realizou seu estudo etnográfico, os afrobrasileiros se descrevem a si mesmos e descrevem outras pessoas recorrendo a cores de pele variadas num esforço de cortesia, mas que, na verdade, acreditam existirem apenas duas raças, a negra e a branca. Hanchard (1994) acredita que, entre ativistas afrobrasileiros do movimento negro, existem sinais fracos e fortes de consciência racial. Desde o período da escravidão, afrobrasileiros constituíram comunidades e organizações exclusivas para negros (BUTLER, 1998). E, mais importante, na sociedade brasileira atual, ativistas afrodescendentes e políticas oficiais, tais como a Lei Federal no. 10.639/03, que exige o ensino de história Africana e afrobrasileira nas escolas públicas, podem gerar ou reforçar uma identidade coletiva pelo reconhecimento da história comum de escravidão. Por isso, este estudo procura avaliar se uma identidade coletiva racial negra está se desenvolvendo entre uma certa parcela da população afrobrasileira. Seguindo a noção de Hanchard, examina uma forma mais fraca e outra mais forte de identidade coletiva racial.

É importante discutir se pardos e negros têm situações econômicas semelhantes. Caso não tenham, é possível que manifestem interesses distintos e que não necessariamente se identifiquem como um só grupo. Isso tornaria inaplicável para o caso brasileiro a utilidade heurística negra de Dawson. Telles (2004) questiona a ideia de Carl Degler da saída de emergência dos mulatos, que sustenta que os pardos são mais bem tratados do que os negros. Mas estudos que revelam que pardos ganham mais que negros no mercado de trabalho ao desempenharem as mesmas funções favoreceriam a teoria de Degler (TELLES, 2004, p.146). Telles examina também a afirmação de Peter Wade (1993) de que a clivagem racial determinante na Colômbia, assim como em outros países latinoamericanos, é entre não-negros e negros, pois esses sofreriam formas mais agudas de discriminação do que os pardos. Wade acredita que a discriminação praticada contra pardos é superestimada e que sua renda média acaba se retraindo por conta de cálculos que a combinam com a de negros que se autoclassificam como pardos. Telles refuta essa ideia com evidências empíricas, apoiando-se na classificação do entrevistador para sua análise, e destacando a importância disso ao avaliar questões relativas à renda, e demonstra como a classificação feita por outras pessoas afeta o desempenho no mercado de trabalho mais do que a autoclassificação. Telles define ainda a oposição entre brancos e não-brancos como a principal clivagem racial, concluindo, ademais, que os dados apoiados na autoclassificação elevam os níveis de renda de pardos e reduzem os de brancos. Considerando a utilidade heurística negra, seus dados revelam que as diferenças de 
renda são muito maiores entre brancos e pardos do que entre pardos e negros. Isso reforça a ideia de que pardos não são mais favorecidos do que negros. Resultados como esses dão razão aos ativistas do movimento negro que defendem a conflação de dados relativos à renda de negros e pardos. Mas, ainda mais importante, se negros e pardos cada vez mais acreditam que ambos os grupos sofrem discriminação de formas similares, isso pode acabar influenciando a formação e a expressão de seus interesses coletivos. Antes de examinarmos a identidade coletiva racial negra, abordaremos a identificação pela cor e a relação entre essa e o voto em favor de candidatos negros.

\section{Análise do voto em favor de um candidato negro}

Aplicamos uma análise de regressão na qual o voto em favor de um candidato negro representa a variável dependente e identificação pela cor, cidade, sexo, idade, status socioeconômico, bairro e identidades coletivas forte e fraca atuam como variávéis independentes ${ }^{2}$. O modelo de regressão mostra que a identificação pela cor e a identidade coletiva fraca são estatisticamente significantes com um intervalo de segurança de $95 \%$, enquanto bairro, idade e status socioeconômico têm sua significância estatística situada num intervalo de segurança de 99\% (Tabela 4). Também uma regressão logística foi aplicada para extrair estimativas de probabilidade para o voto em favor de um candidato negro em função das variáveis independentes (Tabela 5).

Entrevistados foram questionados sobre se haviam votado em um candidato negro, podendo responder sim ou não. A identificação dos entrevistados pela cor se baseia na cor que escolheram na questão aberta. Não incluímos aqueles que se autoclassificaram como indígenas, afrodescendentes e brasileiros. Categorias de cor e raça foram agrupadas da seguinte maneira: branco, mulato, moreno claro, pardo (abrangendo pardo, moreno e marrom), moreno escuro (moreno escuro e moreno jambo), a categoria racial negro (negro e "negão") e a categoria de cor preto. Os níveis educacionais correspondem aos anos de escolarização formal, agrupados assim: 1.3 anos, 4-7, 8.10, 11-14 e mais de 15 anos. A renda familiar mensal engloba: sem renda, renda menor do que 2 salários mínimos, 2.5, 5.10 e 10.20 salários mínimos. O status socioeconômico é medido pela combinação das variáveis educação e renda. As categorias de idade são: 16.25 anos, 26-40, 41.54 e mais de 55 anos. Os bairros são: Federação, Itapuã, Periperi, Brasilândia, Cidade Tiradentes, Casa Verde, Campo Limpo e Capão Redondo.

\footnotetext{
2 Rodamos uma regressão na qual o voto em favor de um candidato negro atua como variável dependente em relação aos fatores identificação pela cor, idade, educação, partido político e uma variável de interação representada por educação e identificação pela cor, que não revelou qualquer significância estatística.
} 
Tabela 4

Análise de regressão do voto em favor de um candidato negro, Salvador e São Paulo

\begin{tabular}{|l|c|c|}
\hline \multicolumn{1}{|c|}{ Votou em candidato negro } & Coeficiente & Erro-padrão \\
\hline Cor & $.17^{* *}$ & .08 \\
\hline Educação*/Renda & $.26^{* *}$ & .10 \\
\hline Idade & $.41^{* * *}$ & .07 \\
\hline Sexo & .03 & .04 \\
\hline Identidade coletiva racial fraca & $.09^{* *}$ & .04 \\
\hline Identidade coletiva racial forte & .01 & .05 \\
\hline Bairro & $.57^{* * *}$ & .08 \\
\hline Constante & $.28^{* *}$ & .09 \\
\hline $\mathrm{N} \mathrm{553}$ & & \\
\hline
\end{tabular}

$* p<.10 * * p<.05 * * * p<.01$

Tabela 5

Regressão logística do voto em favor de um candidato negro, Salvador e São Paulo

\begin{tabular}{|l|c|c|}
\hline \multicolumn{1}{|c|}{ Votou em candidato negro } & Coeficiente & Erro-padrão \\
\hline Cor & $.95^{* * *}$ & .40 \\
\hline Educação*/Renda & $1.80^{* * *}$ & .70 \\
\hline Idade & $2.08^{* * *}$ & .34 \\
\hline Sexo & .26 & .19 \\
\hline Identidade coletiva racial fraca & $.47^{* *}$ & .22 \\
\hline Identidade coletiva racial forte & .07 & .26 \\
\hline Bairro & $1.92^{* * *}$ & .71 \\
\hline Constante & $3.57^{* * *}$ & .49 \\
\hline N 553 & & \\
\hline
\end{tabular}

$* p<.10 * * p<.05 * * * p<.01$

3 O tamanho da amostra é menor do que a amostra original (674) porque alguns dos entrevistados não respoderam todas as questões e, em alguns casos, quando optaram pelas categorias amarelo, indígena ou brasileiro, suas respostas não foram consideradas. 


\section{Idade e voto em candidatos negros}

Tanto a análise de regressão como a regressão logística mostram que identificação pela cor, status socioeconômico, idade, identidade coletiva racial fraca e bairro são todos fatores estatisticamente significantes. A idade é especialmente significante, situando-se em um intervalo de segurança de $99 \%$. Conforme aumenta a idade, aumenta também a probabilidade de que um entrevistado vote em favor de um candidato negro. Mantendo constantes a cor, o bairro, o sexo, o status socioeconômico e as identidades coletivas raciais fraca e forte, a estimativa de probabilidade de que um afrobrasileiro no grupo etário dos 16 aos 25 anos em Salvador e São Paulo vote em um candidato negro é de .30. A probabilidade aumenta para .45 na faixa etária dos 26 aos 40 e para .62 na faixa dos 51 aos 55 anos. Finalmente, para aqueles acima de 56 anos, chega a .76. Afrobrasileiros na faixa etária mais velha são duas vezes e meia mais propensos a votarem em favor de candidatos negros do que afrobrasileiros situados nas faixas mais jovens.

\section{Bairro e voto em candidatos negros}

Há uma relação etatisticamente significante entre o bairro em que vive um entrevistado e o voto em favor de um candidato negro. Em Salvador, $61 \%$ dos entrevistados votaram em um candidato negro, enquanto foram somente $31 \%$ dos de São Paulo que o fizeram. Isso pode ser explicado pelos fatos de que mais políticos afrobrasileiros se candidataram nas eleições em Salvador do que em São Paulo e também de que as categorias de cor são mais flexíveis em Salvador do que em Sâo Paulo (MITCHELL, 2009).

Considerando que um percentual maior de afrobrasileiros tenha votado em candidatos negros em Salvador do que em São Paulo, não surpreende que seja também maior esse percentual em todos os bairros soteropolitanos, em contraste com todos os bairros da capital paulista (Figura 1).

Mantendo constantes as variáveis independentes idade, sexo, status socioeconômico e identidades coletivas raciais forte e fraca, constata-se que, em Salvador, a probabilidade estimada de voto de um entrevistado afrobrasileiro em favor de um candidato negro foi de .74 em Federação, um bairro diversificado em termos socioeconômicos, enquanto em Periperi, com uma população de renda mais baixa, foi de apenas .56. Em São Paulo, o valor mais alto entre todos os bairros paulistanos foi encontrado em Brasilândia, .46. Já no Capão Redondo, foi de .15, e mais baixo de todos. Também foi possível constatar que, no Capão Redondo, apenas $14 \%$ dos entrevistados concordam que afrobrasileiros de todas as cores são negros, o que implica dizer que uma considerável maioria tem uma identidade coletiva bastante baixa. De modo similar, nesse mesmo bairro, 59\% dos 
entrevistados identificaram-se em termos de cor ou raça como não-negros. Levando em conta o impacto da identidade coletiva fraca e da identificação pela cor na propensão ao voto em favor de candidatos negros, não chega a surpreender que o valor ali obtido seja muito baixo. Mais adiante examinamos a significância da identificação pela cor e da identidade coletiva racial fraca na propensão ao voto em candidatos negros.

Figura 1

\section{Estimativa de probabilidade do voto em favor de um candidato negro de acordo} como o bairro do entrevistado

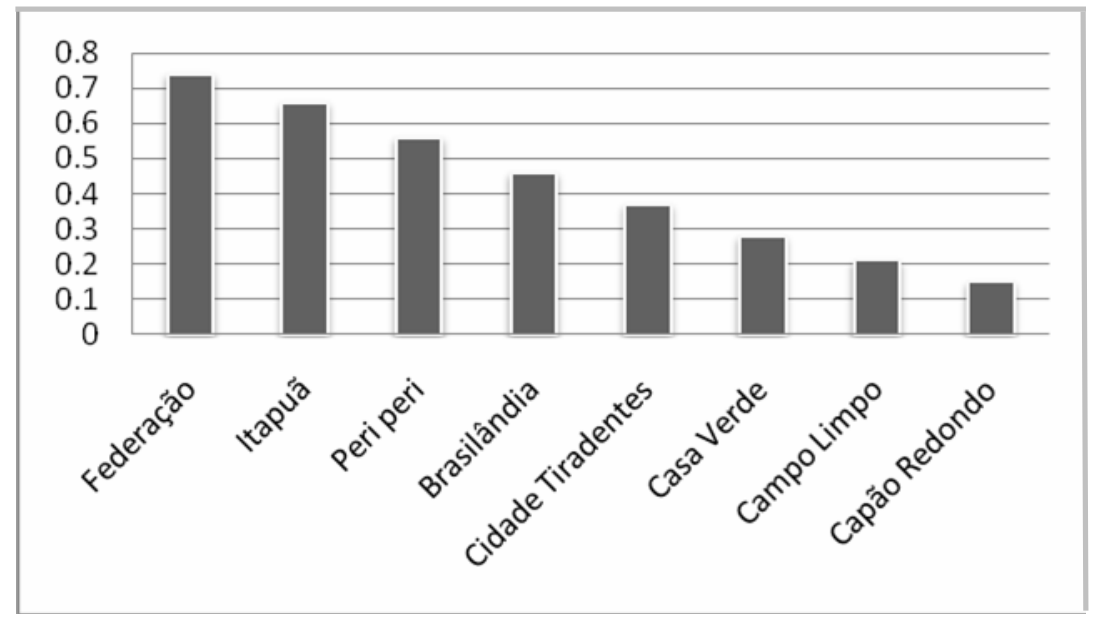

\section{Status socioeconômico e voto em candidatos negros}

À medida que aumenta o status socioeconômico, aumenta também a propensão ao voto em candidatos negros. Sendo composto por níveis de educação, medidos em anos de escolarização formal, e de renda, medidos pela renda familiar mensal, o status socioeconômico apresenta uma significância estatística situada em um intervalo de segurança de 95\%. Mantendo constantes as variáveis independentes identificação pela cor, bairro, sexo, idade e identidades coletivas raciais forte e fraca, constatamos que afrobrasileiros com os níveis mais baixos de educação (1.3 anos) e de renda (sem renda) têm uma propensão de $38 \%$ a votarem em favor de um candidato negro, sendo de $47 \%$ para aqueles com níveis médios e de $67 \%$ para aqueles com os níveis mais altos de educação e renda. Essa é uma constatação importante, pois demonstra que afrobrasileiros com maior status socioeconômico têm maior propensão a votarem em candidatos negros do que aqueles em situação menos favorável. Na verdade, essa propensão é uma vez e 
meia maior entre os afrobrasileiros de status mais alto. Alguns candidatos afrobrasileiros em Salvador e São Paulo admitem pleitear votos junto a afrobrasileiros de classe média e junto àqueles que aceitam sua negritude e se identificam como tais. Porém, outros afirmam procurar apoio entre afrobrasileiros de todas as classes sociais (MITCHELL, 2009). Esses resultados mostram que 0 apelo junto a afrobrasileiros de alto status socioeconômico pode constituir uma estratégia eleitoral viável, na medida em que esses parecem compor um bloco de eleitores aberto às investidas dos candidatos afrobrasileiros.

\section{Identificação pela cor}

Uma das constatações mais importantes deste estudo é a de que a identificação pela cor é estatisticamente significante em um intervalo de segurança de $95 \%$. À medida que as cores se tornam mais escuras, ou à medida que a identificação pela cor se move do branco ao negro no espectro das cores, aumenta a estimativa de probabilidade de que um afrobrasileiro em Salvador e São Paulo vote em um candidato negro (Figura 2). Mantendo constantes as variáveis independentes identificação pela cor, bairro, sexo, idade e identidades coletivas raciais forte e fraca, a estimativa de probabilidade de que afrobrasileiros que se identificam como brancos votem em candidatos negros é de .33, sendo de .43 para os que se identificam como pardos, aumentando ainda mais para os que se identificam como negros, sendo de .50 para os que se identificam pela categoria racial negro e de .54 para os que classificam pela categoria de cor preto. Analisamos separadamente ambas as categorias porque preto representa uma cagtegoria de cor e negro não, sendo sobretudo uma categoria racial politicamente carregada, denotando negritude. A estimativa de probabilidade do voto em favor de candidatos negros entre os entrevistados que se identificaram como pretos é ligeiramente maior do que entre os que se identificaram como negros. Contudo, o que é de fato mais revelador é que um afrobrasileiro que se identifica como negro (seja preto ou negro) é mais do que uma vez e meia mais propenso a votar em candidatos negros do que afrobrasileiros que se identificam como brancos. 
Figura 2

Estimativa de probabilidade do voto em favor de um candidato negro de acordo com a cor do entrevistado em Salvador e São Paulo

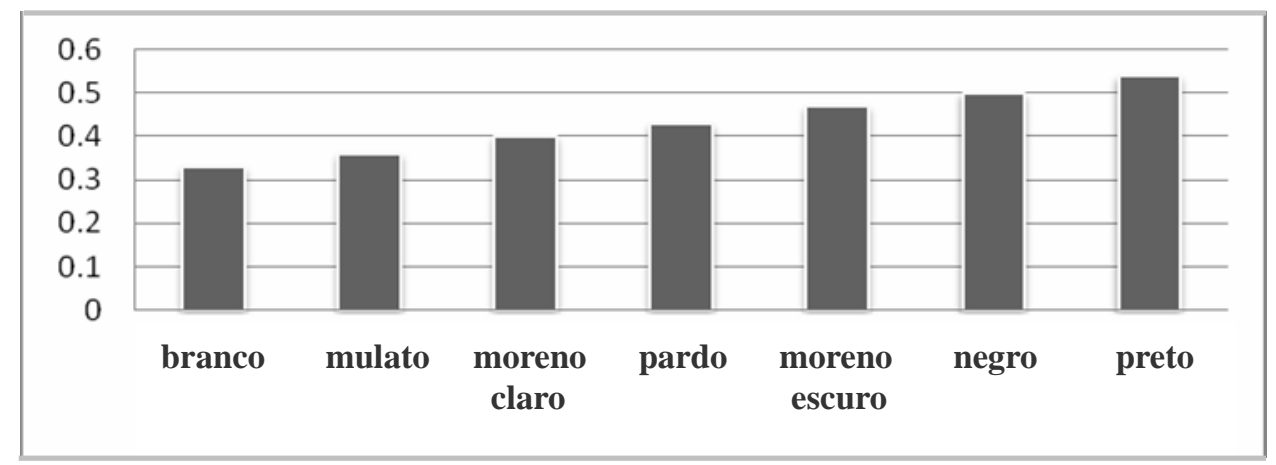

\section{Votos "preto" e "negro"}

A maior estimativa de probabilidade de voto em candidatos negros em ambas as cidades é encontrada entre pretos. Conforme destacado anteriormente, preto é a categoria de cor que denota a cor da pele em lugar da adoção de em uma categoria racial. Apesar disso, ela tem forte significado político, especialmente num país em que a negritude não é suficientemente valorizada nos meios de comunicação ou na vida cotidiana. Afrobrasileiros podem voluntariamente optar por uma categoria não-negra e, ao fazê-lo, geralmente elegem a categoria parda, apesar de um certo número de afrobrasileiros se identificarem como pretos ou negros. Em comparação com as escolhas daqueles que optam por identidades não-negras, preto ainda tende a expressar uma consciência racial mais aguçada da negritude. Por essa razão, são mais propensos a apoiarem candidatos negros do que afrobrasileiros que se identificam por meio de outras categorias de cor. A pesquisa etnográfica de John Burdick (1998) oferece evidências de que pretos enfrentaram pessoalmente situações de racismo com muito mais frequência do que afrobrasileiros que anteriormente se identificavam com uma cor mais clara, passando posteriormente a identificar-se como negros. Diferente de Burdick, não acredito que afrobrasileiros que adotem a categoria preto se vejam condenados a essa opção. Em seu reconhecimento do racismo, são conscientes de sua raça e, em lugar de acatar o mito da democracia racial, segundo o qual a discriminação se deve unicamente à classe social, eles acreditam genuinamente que ela se deve à cor da pele e, em decorrência, elegem uma categoria de cor correspondente. Apesar de existirem diferenças entre pretos e negros, ambas as categorias representam identidades negras e deveriam ser devidamente compreendidas ao se avaliar a 
consciência racial.

A adoção de uma identidade negra é um exemplo revelador de como a raça é politizada. Conforme demonstram dados censitários, o percentual dos que adotam a identidade preta manteve-se relativamente constante. Apenas recentemente houve mudanças nesse aspecto. Atualmente, o número de afrobrasileiros supera o de brasileiros brancos e isso se deve a um aumento no número de afrobrasileiros que se identificam como pretos (WERNECK, 2008). Os dados colhidos para este estudo apontam para o fato de que tanto em Salvador como em São Paulo, líderes e ativistas do movimento negro têm um bloco potencial de eleitores a mobilizar ${ }^{4}$.

\section{Identificação pela cor, bairro e voto em candidatos negros}

Examinamos as probabilidades estimadas de voto em favor de candidatos negros de acordo tanto com o bairro em que residem os entrevistados quanto com sua adscrição conforme categorias de cor ou raça, ao mesmo tempo em que foram mantidas constantes idade, sexo, identidades coletivas raciais forte e fraca e o status socioeconômico. Comparamos os bairros de Casa Verde e Brasilândia, em São Paulo, e Federação, em Salvador. Pelo menos 10\% dos entrevistados em Casa Verde e Federação situam-se na camada mais alta em termos socioeconômicos. Brasilândia, por outro lado, é um caso contrastante, onde $30 \%$ dos entrevistados se situam nas duas camadas mais baixas em termos econômicos. Mantendo idade, sexo, identidades coletivas raciais forte e fraca e a combinação das variáveis educação e renda constantes, afrobrasileiros de Federação são $74 \%$ mais propensos a votarem em candidatos negros, enquanto os de Casa Verde e Brasilândia têm propensões respectivas de 28 e 46\%. Em Casa Verde, afrobrasileiros que se autoidentificaram como brancos ou pardos revelaram propensões de 18 e 25\%, respectivamente. Entre os afrobrasileiros que se identificaram como negros ou pretos, as taxas respectivas foram de 31 e 34\%. Assim, há uma diferença de 16 pontos percentuais entre as propensões respectivas de afrobrasileiros que se identificam como brancos e pretos. Em Federação, afrobrasileiros que se identificaram como brancos apresentaram uma propensão de voto em candidatos negros de $61 \%$, sendo de $71 \%$ entre os que se identificaram como pardos, $77 \%$ entre os negros e $79 \%$ entre os pretos. Em Brasilândia, os números respectivos foram: $33 \%$ entre brancos, $43 \%$ entre pardos, $50 \%$ entre

\footnotetext{
${ }^{4}$ Atualmente, no Brasil, é possível encontrar produtos de limpeza pessoal e cosméticos destinados à "pele morena e negra". Certa vez, quando fazia compras na Avenida Paulista, em São Paulo, perguntei por um creme para as mãos e foi-me prontamente recomendado um produto para pele negra e morena. Um tal produto seria inconcebível há 30 anos. A despeito do fato de que o Brasil é conhecido por sua rica composição demográfica em termos raciais, somente recentemente os empresários começaram a reconhecer e a explorar o potencial de mercado das categorias raciais.
} 
negros e $53 \%$ entre pretos.

Inobstante manter-se a tendência segundo a qual aumenta a propensão de voto em candidatos negros conforme escurecem as cores da autoclassificação, o impacto do local de residência se destaca ainda mais quando se comparam os grupos de cor. Afrobrasileiros que se identificam como pretos em Federação são mais do que duas vezes mais propensos a votarem em favor de candidatos negros do que pretos que moram em Casa Verde. Da mesma forma, afrobrasileiros que se identificam como brancos em Federação são três vezes mais propensos a votarem em candidatos negros do que os de Casa Verde. Ainda de modo similar, para realçar o contraste, afrobrasileiros que se identificam como pretos em Federação são mais do que quatro vezes mais propensos a votarem em candidatos negros do que afrobrasileiros que se identificam como brancos em Casa Verde. O acentuado contraste produzido pelo impacto do local de residência, juntamente com a identificação pela cor, revela-se marcante quando comparações são feitas entre bairros e cores.

Figura 3

Estimativa de probabilidade do voto em favor de um candidato negro de acordo com o bairro e com a autoidenticação pela cor

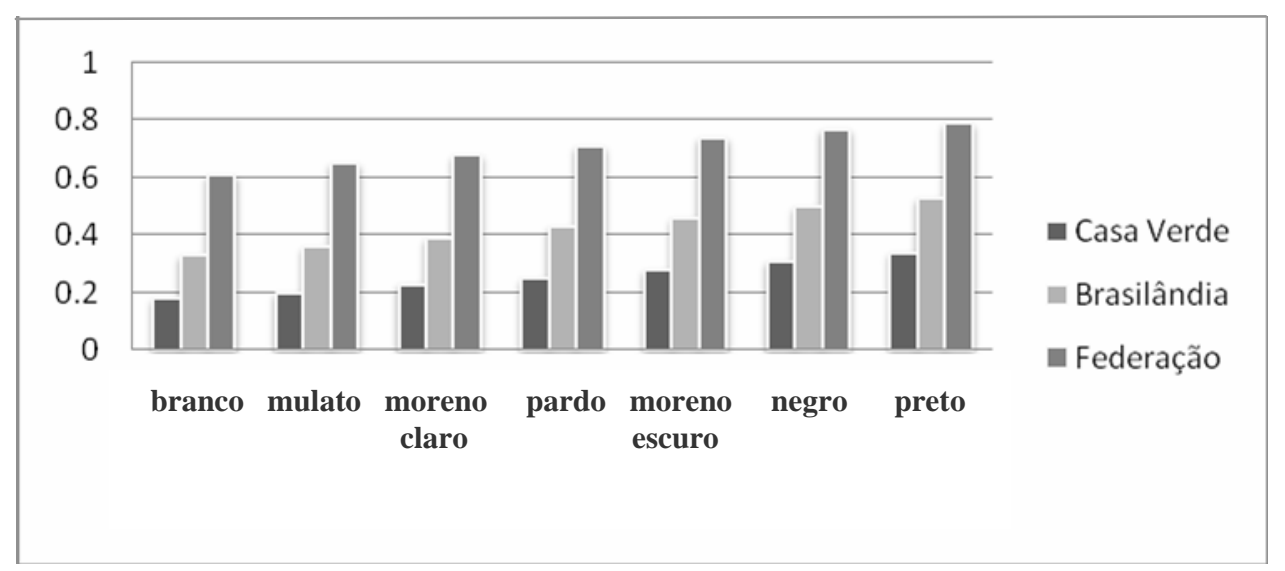




\section{Identificação pela cor e status socioeconômico}

Conforme mencionado anteriormente, a identificação pela cor também afeta a propensão de um afrobrasileiro a votar em candidatos negros. Antes de analisarmos esse resultado, examinamos o efeito do status socioeconômico e da identificação pela cor. Mantendo constantes idade, sexo, bairro e identidades coletivas raciais forte e fraca, a análise demonstra que um afrobrasileiro que se identifica como branco e se situa na camada mais baixa de renda e educação, tem uma propensão de $26 \%$ a votar em candidatos negros, sendo que essa propensão é de $54 \%$ para um afrobrasileiro que se identifica como branco mas se situa na camada mais alta de educação e renda. Portanto, mesmo que um afrobrasileiro se identifique como branco, um alto nível socioeconômico aumenta sua propensão a votar em candidatos negros. Também entre os afrobrasileiros que se identificam como pretos, aqueles com o nível educacional mais baixo revelam uma propensão de $45 \%$, sendo de $73 \%$ entre aqueles com o nível educacional mais alto. Sendo assim, afrobrasileiros de camadas mais altas que se identificam como pretos têm uma propensão mais de duas vezes e meia maior a votar em candidatos negros do que aqueles que se identificam como brancos e se situam na camada mais baixa. Também independente do nível socioeconômico, pretos são quase uma vez e meia mais propensos a votarem em candidatos negros do que afrobrasileiros que se identificam como brancos e se situam na camada mais alta. Renda e educação, portanto, desempenham um papel importante, especialmente ao serem combinadas com raça e cor.

\section{Identidade coletiva racial negra forte e fraca}

Neste estudo, a identidade coletiva racial negra foi examinada através de duas questões. A primeira: "você acredita que afrodescendentes com diferentes cores de pele são negros?" E a segunda: "você acredita que aquilo que afeta os negros também afeta você?" A primeira questão se refere à cor da pele e serve como índice de uma identidade coletiva racial fraca. É essencialmente o que Hanchard (1994) descreve como uma indício leve de consciência racial. Essa forma de consciência é altamente superficial, mas, mesmo assim, reconhece que afrobrasileiros se veem como um grupo racial. Sheriff (2001) constatou que afrobrasileiros tendem a se identificar de acordo com variados tons de pele na tentativa de serem corteses e de não ofenderem seus interlocutores ao identificá-los diretamente como negros, sem, contudo, jamais deixarem de acreditar que todos pertencem conjuntamente à raça negra.

A questão que se refere àquilo que afeta os negros procura medir uma identidade coletiva racial forte ou aquilo que Dawson (1994) chama de utilidade 
heurística negra. Visto que o conceito de Dawson apóia-se fundamentalmente na história dos afroamericanos e nas práticas legais racistas nos Estados Unidos, que favoreceram a persistência de uma identidade coletiva negra, é improvável que uma variante igualmente forte de identidade coletiva tenha emergido no Brasil, por conta de uma história muito diferente de formação histórica dos grupos raciais. Ainda assim, é útil considerar a identidade coletiva racial forte, em razão das mudanças recentes na política racial brasileira. Trata-se, portanto, de algo que os pesquisadores deverão cada vez mais levar em conta futuramente.

Em nossa amostra, $78 \%$ dos afrobrasileiros em Salvador e $64 \%$ daqueles entrevistados em São Paulo acreditam que afrodescendentes de diferentes cores são negros. Em Salvador, $87 \%$ dos afrobrasileiros entrevistados concordam com a afirmação de que aquilo que afeta os negros também os afeta, enquanto em São Paulo o número é $77 \%$ (Tabela 6). Afirmar que o que afeta os negros também afeta a pessoa entrevistada é o indicador de uma identidade coletiva racial forte porque não se trata de algo meramente superficial ou relacionado exclusivamente com a cor da pele. Pelo contrário, revela uma crença no fato de que, independente de se tratar de racismo ou de outros desafios ou obstáculos relativos à raça, a pessoa acredita que isso também a afetará pessoalmente.

Tabela 6

Afrobrasileiros que acreditam que afrodescendentes de diferentes cores de pele são negros e afrobrasileiros que acreditam que aquilo que afeta os negros também os afeta pessoalmente

\begin{tabular}{|c|c|c|c|c|}
\hline & \multicolumn{2}{|c|}{ Salvador (\%) } & \multicolumn{2}{c|}{ São Paulo (\%) } \\
\hline & $\operatorname{Sim}$ & Não & Sim & Não \\
\hline $\begin{array}{c}\text { Diferentes cores são } \\
\text { negros }\end{array}$ & 78 & 22 & 64 & 36 \\
\hline $\begin{array}{c}\text { Afetando negros, } \\
\text { afeta a mim }\end{array}$ & 87 & 13 & 77 & 23 \\
\hline
\end{tabular}


Tabela 7

Autoidentificação pela cor e crença de que afrodescendentes de todas as cores são negros

\begin{tabular}{|c|c|c|c|c|}
\hline & Salvador & & São Paul & \\
\hline & $\operatorname{sim}(\%)$ & Não (\%) & $\operatorname{sim}(\%)$ & Não (\%) \\
\hline Branco & 75 & 25 & 47 & 53 \\
\hline Mulato & 75 & 25 & 100 & 0 \\
\hline Moreno claro & 67 & 33 & 50 & 50 \\
\hline Pardo & 70 & 30 & 56 & 44 \\
\hline Moreno escuro & 0 & 0 & $100 *$ & 0 \\
\hline Negro & 82 & 18 & 73 & 27 \\
\hline Preto & 86 & 14 & 63 & 37 \\
\hline
\end{tabular}

Em Salvador, os afrobrasileiros que se identificaram como pretos apresentaram o maior percentual de concordância com a afirmação de que afrobrasileiros de diferentes cores são negros, sendo seguido pelos negros, dos quais $82 \%$ concordaram (Tabela 7 ). Entre os afrobrasileiros que se identificaram como brancos e mulatos, $75 \%$ acreditam na afirmação, sendo de apenas 70 e $67 \%$ os percentuais de concordância respectivos de morenos claros e pardos. Em São Paulo, $100 \%$ dos mulatos e morenos escuros concordam, $73 \%$ dos negros, $63 \%$ dos pretos e, sem razão para surpresa, somente $47 \%$ dos afrobrasileiros que se identificam como brancos, revelando o menor percentual de identidade coletiva racial fraca entre todos os grupos de cor e raça.

As respostas dos afrobrasileiros entrevistados à pergunta relativa a serem afetados pelo que afeta os negros ajudam a compreender como eles percebem a identidade coletiva racial forte. Eis algumas:

"Se alguém sofre preconceito racial, isso também me afetará. Você tem empatia e a verdade é que estamos todos no mesmo barco. Aquilo que é ruim para um (negro) é ruim para mim também. Temos de nos unir para lutarmos juntos contra diversos tipos de preconceito." (Jovem afrobrasileiro, 27 anos, São Paulo, entrevistado pela autora em novembro de 2008)

"Acho que sim. Estou acostumada a dizer a meus filhos que negro é negro onde quer que se esteja pelo mundo. Algumas vezes, situações ruins que acontecem com você como negro aqui são as mesmas que acontecem com os negros nos Estados Unidos ou com 
franceses negros, algo que se tornou visível quando há 3 anos saímos às ruas para protestar. Assim, negro é negro no mundo todo; seja na África ou na diáspora." (Ativista do movimento negro que se identifica como negra, 45 anos, Salvador, entrevistada pela autora em novembro de 2008)

"Há questões que afetam toda a população negra. Por exemplo, estereótipos raciais a respeito de negros, a respeito do que significa ser negro, a desvalorização da consciência cultural dos negros, isso afeta basicamente a todos... Eu nem sempre sou afetado diretamente porque sou um professor universitário e considerado uma pessoa de classe média, alguém que estudou e tem educação. Portanto, nem sempre sou afetado, mas em outros aspectos, mais gerais... tais como preconceito sob a forma de estereótipos (sim, sou afetado)." (Professor universitário que se identifica como negro, 44 anos, Salvador, entrevistado pela autora em novembro de 2008)

A partir dessas entrevistas, torna-se evidente que afrobrasileiros educados ou engajados em organizações do movimento negro acreditam pertencer a um grupo racial negro. Ao mesmo tempo em que reconhece que seu status socioeconômico previne que seja exposto a certos tipos de preconceito, o professor universitário reconhece que existem estereótipos a respeito de negros que também o afetam, independente de sua classe social. Em geral, todos os entrevistados discutem os desafios e obstáculos enfrentados pelos afrobrasileiros e reconhecem que são igualmente afetados como tais. Um dos entrevistados disse acreditar que as dificuldades que os negros enfrentam são as mesmas, quer estejam no Brasil ou em outros países. Fica evidente a partir dessas entrevistas que a identidade coletiva racial compartilhada baseia-se em uma reação ao preconceito que afrobrasileiros enfrentam em decorrência de sua raça. 


\section{Identidade coletiva racial negra e preferência eleitoral}

Nossa hipótese inicial era que afrobrasileiros que se identificam como membros de um grupo racial são mais propensos a votarem em candidatos negros do que aqueles que não se identificam da mesma forma. Para testá-la, examinamos uma forma forte e outra fraca de identidade coletiva racial e aplicamos uma regressão com o voto em favor de um candidato negro como a variável dependente e idade, sexo, bairro, status socioeconômico e identidades coletivas raciais forte e fraca como variáveis independentes. A variante forte da identidade coletiva racial não se revelou estatisticamente significante, mas a variante fraca sim, em um intervalo de segurança de 95\%. Mantendo constantes todas as variáveis independentes, constatamos que afrobrasileiros com uma identidade coletiva racial fraca têm uma propensão de $50 \%$ a votarem em candidatos negros, em contraste com $39 \%$ entre os que não acreditam na variante fraca da identidade coletiva racial.

Para avaliar o impacto da identidade coletiva racial fraca em conjunto com a identificação pela cor e o status socioeconômico, comparamos três casos: um afrobrasileiro que se identifica como branco, tem uma identidade coletiva racial fraca e se situa na camada socioeconômica mais alta terá uma propensão de $57 \%$ a votar em favor de um candidato negro. Já a de outro afrobrasileiro, que se identifica como pardo, tem uma identidade coletiva racial fraca e o nível educacional mais alto, será de $67 \%$. Essa propensão cairá dramaticamente, para $20 \%$, no caso de um afrobrasileiro que se identifica como branco, tem o nível socioeconômico mais baixo e nenhuma forma de identidade coletiva racial. Isso faz com que a propensão de um afrobrasileiro com essas características a votar em candidatos negros seja três vezes menor do que a de afrobrasileiros que se identifiquem como pardos ou brancos e tenham nível socioeconômico alto. Combinando o impacto que o bairro em que o entrevistado reside tem sobre a estimativa da propensão de voto com a identificação pela cor e uma identidade coletiva fraca, um afrobrasileiro com o mais alto nível socioeconômico que resida em Federação, Salvador, terá uma propensão de $89 \%$. Mas ela cairá para ínfimos $10 \%$ caso o afrobrasileiro não tenha qualquer identidade coletiva, se identifique como branco, tenha o nível sócio-econômico mais baixo e resida em Casa Verde (SP), o que representa uma diferença de 79 pontos percentuais. Analisar os dados dessa forma revela a importante dinâmica interação da identidade coletiva racial, da identificação pela cor, do status socioeconômico e do bairro sobre a probabilidade do voto em prol de um candidato negro. 


\section{Conclusão}

Uma ampla maioria de afrobrasileiros em Salvador e São Paulo se identifica com formas fracas ou fortes de identidade coletiva racial. Mesmo assim, entre as duas, somente uma forma fraca foi estatisticamente significante nos modelos de regressão e logísticos apresentados. Além disso, idade, identificação pela cor, status socioeconômico e bairro são todos estatisticamente significantes. A hipótese inicial de que afrobrasileiros que se identificam como um grupo racial negro favoreçam candidatos negros foi confirmada para aqueles que demonstram uma identidade coletiva racial fraca. E mais, em ambas as cidades, há uma tendência segundo a qual, à medida que os afrobrasileiros se identificam pela cor ao longo de um espectro que vai de branco a negro, cresce a propensão a votarem em candidatos negros. Isso é uma constatação importante, que demonstra as implicações políticas da identificação pela cor. Se o número de afrobrasileiros que se identificam como negros continuar aumentando, é possível que mais candidatos negros sejam eleitos. No futuro, isso poderia ajudar a reduzir a sub-representação dos afrobrasileiros na política eleitoral.

\section{Referências Bibliográficas}

BAILEY, S. R. e TELLES, E. E. "Multiracial vs. Collective Black Categories: Census Classification Debates in Brazil". Ethnicities , v.6, nº 1, 2006.

BRUBAKER, R. e COOPER, F. "Beyond Identity". Theory and Society, n 8, 2000.

BUTLER, K. Freedoms Given, Freedoms Won: Afro-Brazilians in Post-Abolition São Paulo and Salvador. News Brunswick: NJ: Rutgers University Press, 1998.

CASTRO, M. "Raça e Comportamento Político". Dados , n 36, 1993.

DAWSON, M. Behind the Mule: Race and Class in African American Politics. Princeton, NJ: Princeton University Press, 1994.

Black Visions: The Roots of Contemporary African-American Political Ideologies. Chicago: University of Chicago Press, 2001. 
GUIMARÃES, A. S. The Race Issue in Brazilian Politics (The Last Fifteen Years). Fifteen Years of Democracy in Brazil Conference. Trabalho apresentado no Instituto de Estudos Latino-Americanos da Universidade de Londres, Inglaterra, fev. 2001.

HAGOPIAN, F. Traditional Politics and Regime Change in Brazil. New York: Cambridge University Press, 1996.

HANCHARD, M. Orpheus and Power: The Movimento Negro of Rio de Janeiro and São Paulo, Brazil, 1945-1988. Princeton, NJ: Princeton University Press, 1994.

JOHNSON III, O. Locating Blacks in Brazilian Politics: Afro-Brazilian Activism, New Political parties, and Pro-Black Public Policies. Mimeo, 2006.

. "Black Participation in Brazilian Politics". Journal of Interamerican Studies and World Affairs, v.40, $\mathrm{n}^{\circ} 4,1998$.

MAINWARING et al. Conservative Parties, Democracy, and Economic Reform in Contemporary Brazil. In: MIDDLEBROOK, K. Conservative Parties, the Right, and Democracy in Latin America, 2000.

MITCHELL, G. "Afro-Brazilian Politicians and Campaign Strategies: A Preliminary Analysis". Latin American Politics and Society, 2009.

Politicizing Blackness: Afro-Brazilian Color Identification and Candidate Preference. In: REITER, B. e MITCHELL, G. Brazil's New Racial Politics. Lynne Rienner Publishers, 2009.

MITCHELL, M. Racial Consciousness and the Political Attitudes and Behavior of Blacks in São Paulo, Brazil . Tese de doutorado, Indiana University, 1977.

Race and Democracy in Brazil: The Racial Factor in Public Opinion. National Conference of Black Political Scientists, San Francisco, California, mar.2007.

OLIVEIRA, C. L. P. A Inevitável Visibilidade de Cor: Estudo comparativo das campanhas de Benedita da Silva e Celso Pitta às prefeituras do Rio de Janeiro e São Paulo, nas eleições de 1992 e 1996. Tese de doutorado, Instituto Universitário de Pesquisa do Rio de Janeiro (luperj), 2007.

A Luta por um Lugar: Gênero, Raça, e Classe: Eleições Municipais de Salvador-Bahia, 1992. Série Toques, Programa A Cor da Bahia-UFBA, 1997.

SANSONE, L. Blackness Without Ethnicity: Constructing Race in Brazil. New York: Palgrave Macmillan, 2003. 
SANTOS, S. A. A Ausência de uma Bancada Suprapartidária Afro-Brasileira no Congreso Nacional (Legislatura 1995/1998). Brasília: Centro de Estudos Afro-Asiaticos, 2 Volumes, 2000.

SAWYER, M. Racial Politics in Post-Revolutionary Cuba. New York: Cambridge University Press, 2006.

SHERIFF, R. E. Dreaming Equality: Color, Race, and Racism in Urban Brazil. Piscataway: Rutgers University Press, 2001.

SOARES, G. A. D. e VALLE SILVA, N. do. "Urbanization, Race, and Class in Brazilian Politics". Latin American Research Review, v.22, n² 2, 1987.

SOUZA, A. de. "Raça e Política no Brasil urbano". Revista de Administração de Empresas, Rio de Janeiro, v. 11, n 4, 1971.

TELLES, E. Race in Another America: The Significance of Skin Color in Brazil. Princeton, NJ: Princeton University Press, 2004.

TWINE, F. W. Racism in a Racial Democracy: The Maintenance of White Supremacy in Brazil. New Brunswick: Rutgers University Press, 1998.

VON METTENHEIM, K. The Brazilian Voter: Mass Politics in Democratic Transition: 1974-1986. Pittsburgh, PA: University of Pittsburgh Press, 1987.

WADE, P. Blackness and Race Mixture: The Dynamics of Racial Identity in Colombia. Baltimore: Johns Hopkins University Press, 1993.

WERNECK, F. "Com 49,7\%, Pretos e Pardos Superam Brancos". Estado de São Paulo, 18 set.2008, disponível em:

<http://www.estadao.com.br/economia/not_eco244361,0.htm>, 2008.

Gladys Mitchell - gladysmitchell@yahoo.com

Tradução do original em inglês de Sebastião Nascimento

Recebido para publicação em junho de 2008.

Aprovado para publicação em janeiro de 2009. 